\title{
Taiwanese middle school students' materialistic concepts of sound
}

\author{
Haim Eshach, ${ }^{1,2}$ Tzu-Chiang Lin, ${ }^{2}$ and Chin-Chung Tsai ${ }^{2}$ \\ ${ }^{1}$ Department of Science and Technology Education, Ben Gurion University of the Negev, \\ Beer Sheva 8410501, Israel \\ ${ }^{2}$ Graduate Institute of Digital Learning and Education, \\ National Taiwan University of Science and Technology, Taipei 106, Taiwan
}

(Received 17 September 2015; published 4 March 2016)

\begin{abstract}
This study investigated if and to what extent grade 8 and 9 students in Taiwan attributed materialistic properties to sound concepts, and whether they hold scientific views in parallel with materialistic views. Taiwanese middle school students are a special population since their scores in international academic comparison tests such as TIMSS and PISA are among the highest in the world. The "Sound Concept Inventory Instrument" with both materialistic and scientific statements of sound concepts was applied to explore Taiwanese students' ideas and corresponding confidence. The results showed that although the subject of sound is taught extensively in grade 8 in Taiwan, students still hold materialistic views of sound. The participants agreed, on average, with $41 \%$ of the statements that associate sound with materialistic properties. Moreover, they were quite confident in their materialistic answers (mean $=3.27$ on a 5-point Likert scale). In parallel, they also agreed with $71 \%$ of the scientific statements in the questions. They were also confident of their scientific answers (mean $=3.21$ ). As for the difference between grade 8 and 9 students, it seems that in grade 9, when students do not learn about sound, there is a kind of regression to a more materialistic view of sound. The girls performed better than the boys $(t=3.59, p<0.001)$. The paper uses Vosniadou and Brewer's [Cogn. Sci. 18, 123 (1994).] framework theory to explain the results, and suggests some ideas for improving the teaching of sound.
\end{abstract}

DOI: 10.1103/PhysRevPhysEducRes.12.010119

\section{INTRODUCTION}

The concept of sound obviously relates to many daily phenomena and thus may be considered what Layton [1] called "useful knowledge" for students, helping them to understand their surroundings. Sound is a wave phenomenon. Wave phenomena are ubiquitous and, according to Caleon and Subramaniam [2], ideas related to waves have generality in physics and in other areas. In physics, an understanding of waves may contribute significantly to the comprehension of both classical and modern physics [3-5]. Thus, identifying the preconceptions that prevent students from properly understanding sound phenomena is valuable and deserves a central place within the physics curriculum; it should also be addressed in science education research $[4,5]$. Unfortunately, empirical studies on students' conceptual understanding in physics have concentrated on mechanics, electricity, and magnetism, while researchers have paid less attention to the wave concept [2]. According to those who investigated high school students' conceptions of waves, most foregoing studies on the topic have concentrated on university students. The comparatively

Published by the American Physical Society under the terms of the Creative Commons Attribution 3.0 License. Further distribution of this work must maintain attribution to the author $(s)$ and the published article's title, journal citation, and DOI. few studies that included samples from other academic levels provided limited perspectives, as they either applied research tools with few items or recruited small-size samples. The present paper, which is quantitative in nature, examines 732 Taiwanese middle school students' materialistic conceptions of sound. Taiwanese middle school students are a special population as their scores in international comparisons of academic performance such as TIMSS (grade 8 Taiwanese students ranked number 2 in science) and PISA (grade 9 and 10 ranked among the highest) [6,7] are among the highest in the world.

The focus of this study is on students' materialistic thinking. Based on a literature review, Caleon and Subramaniam [2] have concluded that students often apply object-based reasoning to deal with sound. Object-based reasoning is part of what is known in the literature as materialistic reasoning. As we will show in the literature review section, students not only view sound as a kind of actual object but also, at times, as a liquid or invisible material. Furthermore, the existing research usually relates to materialistic thinking as a whole, not to the different characteristics of materialistic thinking. For instance, questions such as the following have barely been addressed in the literature: to what extent, if at all, do students perceive sound as being able to be pushed but not as being influenced by gravity? To what extent, if at all, do students view sound as being able to be contained but not as being able to pass through a vacuum? Understanding whether 
good performing students in science such as Taiwanese students hold materialistic views of sound, and the extent to which they associate sound with different materialistic characteristics, even after learning about sound extensively, might shed light on the nature of materialistic thinking. Such an understanding might also assist educators in designing more efficient learning environments.

In addition, most of the studies on students' conceptual understanding of sound have investigated Western students. Although this study is not a cross cultural one, yet, the fact that its population is from Asia might also shed light on the question of whether materialistic reasoning is universal. Stavy, Goel, Critchley, and Dolan [8] asked the following in their paper: Are intuitive rules universal? In light of such interest in cultural differences, it is also legitimate to ask whether and to what extent materialistic thinking is found in the reasoning of students who have grown up in an eastern culture. This is especially interesting since materialistic thinking is influenced by language [5,9]. This further strengthens the uniqueness of this study.

Also, as an addition to the few papers existing in the literature on middle students' concepts of sound $[4,5,10]$, this paper might broaden our understanding of the barriers students are confronted with when dealing with soundrelated phenomena as well as with the nature of materialistic thinking.

\section{A. Middle school students' concepts of sound}

From those few studies that do exist, it seems that sound, which is a common phenomenon that we experience every day, is an area in which students display numerous difficulties. Boyes and Stanisstreet [10] examined middle school students' conceptions of the path of sound between a source and a listener. The results showed that only about $40 \%$ of the younger pupils (aged 11-13) and $78 \%$ of the older group (aged 13-16) indicated that sound travels from the source to the hearer. Asoko, Leach, and Scott [11] investigated pupils between the ages of 4 and 16, and found that younger children often link the production of sound with their own actions, or consider sound to be a part of the object from which it originated. In addition, Asoko, Leach, and Scott [11] found that the notion of sound traveling within the air existed only amongst 16 year olds (having a $70 \%$ reference within this group).

Chi and colleagues [12-14] suggested that students' misconceptions are attributable to a mismatch between the ontological categories to which subjects assign concepts and the ontological categories to which concepts usually belong. Two main ontological categories which students assign concepts to are substance and process. Chi et al. [14] argued that novices seem inclined toward materialistic or substance-based conceptions when it comes to describing abstract scientific concepts. In physics, for example, students have trouble understanding concepts such as electrical current, heat, and light because they assign these entities to the category of "matter" when in fact they belong to the ontological category of "processes" [9]. For instance, students may perceive electric current as a kind of "electricity juice" or "electron juice" which is the current itself and which flows from one end of a wire to the other, rather than viewing it as a process involving the entire circuit, including material elements such as electrons. This was also found to be valid for the case of sound [15]. Several studies have identified a tendency towards materialistic perceptions of sound amongst middle school students. For instance, studies have suggested that middle school students may envisage sound as an invisible object with dimensions which requires space in order to move $[16,17]$. West and Wallin [18] also found that students aged 10-14 held materialistic views of sound. They further found that a 6-12 hour course on sound, hearing, and auditory health yielded a shift to a more scientific view of sound.

Eshach and Schwartz [5] used Reiner et al.'s [9] substance schema - properties that are common to material substances and that may be extended generally to describe any material substance - to examine whether middle school students possess materialistic thinking of sound. They recommended the necessity to revise Reiner et al.'s [9] substance scheme and to fit it to the case of students' materialistic thinking about sound. Later, Eshach [4] developed the Sound Concept Inventory Instrument [(SCII), for more details of this instrument, see the Method section], which uses the following materialistic list of characteristics named the substance scheme of sound, according to which students may associate sound with.

(A) Sound is invisible material;

(B) Sound has a corpuscular nature—having surface and volume;

(C) Sound is pushable by objects - able to push and be pushed by objects;

(D) Sound is pushable by media—able to push and be pushed by media;

(E) Sound is frictional-experiencing "drag" when moving in contact with some surface;

(F) Sound is containable-able to be contained by something;

(G) Sound is consumable - capable of being depleted;

(H) Sound is gravity sensitive-falls down when dropped;

(I) Hearing is influenced by the sound particle's size or number;

(J) Sound is able to pass in a vacuum-according to Hrepic, Zollman, and Rebello's [3] view that sound may propagate through the vacuum indicates that sound is perceived as an independent kind of material.

Eshach [4] tested the SCII on 355 ninth grade students from across Israel. Overall, the percentage of correct answers to the entire instrument was found to be $27 \%$. 
The results also showed that the students associated sound with both material and process properties. The percentage of distractors indicating process properties that the students marked as "correct" was higher than the percentage of distractors indicating materialistic properties that they marked as "incorrect" (39.47\% vs $23.42 \%$ ). This means that the students agreed with about $75 \%$ of the distractors that indicated that sound has material properties-reflecting a materialistic concept of sound, and with about $40 \%$ of the distractors that indicated process properties-reflecting an association of sound with process. In Israel, unlike in Taiwan, students do not learn the concept of sound in middle school (for a short description of what they do learn concerning sound, see Ref. [4]).

The present paper examines Taiwanese middle school students' concepts of sound. In Taiwan, as will be detailed in the methodology section, grade 8 students learn extensively the concept of sound. It is therefore interesting to examine whether the learning process of the Taiwanese students who, as has been previously mentioned, are among the highest scorers in international standardized assessments, enables them to overcome the barrier that materialistic thinking poses.

\section{B. Research questions}

The aim of this research was to examine Taiwanese middle school students' conceptions of sound. More specifically, the following questions were addressed:

(1) To what extent, if any, do students attribute materialistic properties to sound?

(2) To what extent, if any, (a) do students hold scientific views of sound? And (b) hold both materialistic and scientific views of sound?

(3) Are there differences between grade 8 and 9 students in their scientific and materialistic views of sound?

(4) Are there differences between boys and girls in their scientific and materialistic views of sound?

\section{METHOD}

\section{A. Participants}

A total of 732 middle school students in Taiwan participated in the study. The gender and grade level distribution is shown in Table I. The percentages of female and male students are almost equal. However, grade 8 students constitute the majority of the participants. The difference in the sample sizes of the Grade 8 and 9 students

TABLE I. Distribution of the participants.

\begin{tabular}{lccc}
\hline \hline & Grade 8 & Grade 9 & Total \\
\hline Females & 312 & 52 & $368(50.27 \%)$ \\
Males & 302 & 66 & $364(49.73 \%)$ \\
Total & $614(83.88 \%)$ & $118(16.12 \%)$ & 732 \\
\hline \hline
\end{tabular}

stems from the fact that the Grade 9 students in Taiwan were facing a nationwide entrance examination which discouraged many teachers' assistance in collecting research data due to course time concerns. Grade 8 students in Taiwan study the subject of sound extensively. The curriculum regarding the concepts of sound consists of 12 to 15 hours of classes which cover the following topics: definition of wave, transverse and longitudinal waves, formation and sources of waves, propagation of mechanical and nonmechanical waves, and the propagation of sound waves. The curriculum also includes an introduction of musical instruments such as the guitar and erhu (a traditional Chinese stringed instrument), sound-related phenomena such as echo, ultrasonic and sonar, as well as the concepts of volume, amplitude, decibel, and the function of oscilloscopes.

\section{B. Instrument}

The SCII [4] used is a student-centered instrument which means that students are provided with predefined answers that do not reflect the ideas that the instrument's developers believe students might have. Rather, the predefined answers are based on students' known misconceptions. This approach bases its assumptions on empirical records of false perceptions students are known to have had. This basis may bring an unusually high degree of validity to the instrument's distracters, because the meaning that students read into the instrument choices tends to be the same meaning that they would express if they were spontaneously verbalizing their own views in an interview [19]. Furthermore, for each question, students can provide their own answers if they do not agree with the predefined answers they are provided with. The instrument was validated by 7 experts. The reliability of the SCII, KR20 (which measures the internal consistency of a test and is the most common method used to determine such instrument's reliability [20]) was found to be 0.91 . The instrument includes 20 questions and 71 possible response items; 48 items attribute materialistic properties to sound, and the rest (i.e., 23) present the scientific answers. For each response, students have to decide whether it is true or false and to what degree they feel confident in their answer on a 1-5 confidence scale. Here is an example of a question taken from the instrument (question number 2 in the SCII) and its five responses:

- When we strum a guitar string, we hear a sound because:

(a) The vibrating string releases sound particles and pushes them outward so they reach our ears. True/False. Confidence level in answer: 1, 2, 3, 4, 5.

(b) Each string releases and pushes outward sound particles of different sizes, and that's why they make different sounds. True/False. Confidence level in answer: 1, 2, 3, 4, 5. 
(c) The sound particles are actually in the air. The vibrating string pushes them. Because they are pushed with varying force, we hear different sounds. True/False. Confidence level in answer: $1,2,3,4,5$.

(d) A vibrating string causes changes in the density and pressure of the air around it. This change travels to our ears and enables us to hear. True/ False. Confidence level in answer: 1, 2, 3, 4, 5.

(e) None of the above choices fits my basic viewpoint. My basic viewpoint is (please explain your viewpoint in the space provided below).

Take this question as an example; items a, b, and c attribute materialistic characteristics to sound (materialistic property items), while item d presents the scientific answer that students are expected to know (process property items). When calculating scores in materialistic property items, "True" answer to each of these items scores one point for their agreement with materialistic property of sound. The "False" answer of such items, respectively, contributes one point to the correctness of material property. Moreover, the respondents' "True" answers to any process property item in the SCII scores one point for both their agreement and correctness regarding scientific view of sound. Based on the data collected in this study, we calculated the mean scores of correctness in the entire SCII (71 items), process property items ( 23 items), as well as materialistic property items (48 items). Mean scores of the participants' agreement on both process property items and materialistic property items were also counted.

We translated the SCII into Mandarin and applied it to examine Taiwanese students' concepts. The translation was made from English into Mandarin, and vice versa, until there was complete agreement between the two versions. The translation was made by experts (two physicists and one science educator who are also researchers in science education, and two experienced middle school teachers) who also approved that the instrument is appropriate for Taiwanese students. This process further strengthens the validity of the SCII instrument.

\section{ANALYSIS AND RESULTS}

The analysis and results section is organized as follows: We begin by describing how we dealt with the problem of guessing. We then present general results, i.e., the percentages of correct answers of all the students to the entire questionnaire, and hence answer the proposed research questions in this study.

\section{A. Students' faithful concepts of sound rather than guessing}

Inherent in the family of multiple-choice tests is the limitation of differentiating correct responses due to adequate understanding from those due to guessing [21]. For instance, in a multiple choice questionnaire in which each question has 4 possible answers, if indeed the students guessed, there is a chance of $25 \%$ being right because of guessing. Usually this issue is not addressed since there are many questions, and the assumption is that if indeed the students guessed, they did not do so in all of the questions. So, this phenomenon, in general, is neglected. However, this concern may be addressed by asking the students to provide their confidence rating for each question, which measures the level of confidence of the respondents in their answers [2]. Confidence rating can be regarded as an individual's "internal, estimated belief" in his or her own accuracy [22]. In the present case, for each statement, students should decide whether or not they agree. Accordingly, while the power of such an instrument is that we can examine if the students hold materialistic or scientific views of sound for each question, simultaneously, if they guessed, there is a 50\% chance that they were correct because of guessing. Besides the intrinsic value of the selfconfident rating to ensure that the students were not guessing (see, for instance, Ref. [2]), we also created two scales of scoring. One scale is just the sum of correct answers [1 for correct answer and $(-1)$ for incorrect answer]. The other scale considered the confidence level of each item by creating a weighted value achieved by the multiplication of the score of each statement by its confidence $[1 *$ confidence level for correct items and $(-1)^{*}$ confidence level for wrong answers]. We then summed the weighted scores and calculated the correlation between the two. The correlation was found to be 0.97 . If the students were just guessing and not thinking carefully about their answers, then they would probably randomly select the level of confidence as well. Thus, in such a case, no correlation would be expected between the weighted and the original scores. The high correlation which was found decreases the risk that the students were guessing. Since the correlation is high, we refer in what follows only to the unweighted scores.

TABLE II. Mean of correct answers and confidence.

\begin{tabular}{lccc}
\hline \hline Issue (number of items) & KR-20 & Mean of correct answers (SD) & Mean of confidence (SD) \\
\hline Entire instrument (71 items) & 0.75 & $0.50(0.11)$ & $3.25(0.86)$ \\
Process properties (23 items) & 0.73 & $0.71(0.17)$ & $3.21(0.87)$ \\
Materialistic properties (48 items) & 0.88 & $0.59(0.18)$ & $3.27(0.87)$ \\
\hline \hline
\end{tabular}




\section{B. General results}

As Table II shows, the KR-20 of the entire instrument is 0.75 , which is an acceptable value for an instrument such as this $[23,24]$. The KR-20 results of the scientific and materialistic distractors are also quite satisfactory $(0.73$ and 0.88 , respectively). Overall students' percentage of correct answers-agreeing with the scientific views and disagreeing with the materialistic distractors in the instrument- to the entire instrument is $50 \%$. Also, we can see from the table that the students were confident in their answers for the entire instrument (3.25 out of 5) as well as for its main categories (scientific answers, 3.21 and material, 3.27).

\section{Distribution of students' correct answers for each of the sound substance scheme characteristics}

As can be seen in Fig. 1, students' percentage of correct answers for each of the substance scheme characteristics was quite low (between 30\% and 60\%). This means that students associate all of the materialistic characteristics with sound. Grade 8 students showed less materialistic thinking, relating to most of the sound scheme characteristics, than the grade 9 students. It is worth noting that the grade 8 and 9 patterns of correct answers are quite similar. For instance, both grade 8 and 9 students' correct answers to statements associating sound with gravity (statements 13b, 16a, and 16b, in the SCII) as well as associating sound with the capability of passing through a vacuum (statements 9B, 13E, and 20C in the SCII) $(\sim 60 \%$ and $\sim 50 \%$, respectfully, on average, for grade 8 and grade 9 students) were higher than those associating sound with the other characteristics. The answers to statements associating hearing with the size and number of sound particles are low in both groups (statements 1a, 2b, 8b, 8c, 12a, 12b, 19b in the SCII) ( 30\%, on average, for both groups).

\section{The extent to which students attribute materialistic properties to sound in parallel to holding scientific views of sound}

To address the question of whether the students hold both materialistic and scientific views of sound simultaneously, we did the following: (i) We divided the students into 5 levels of agreement with materialistic properties. That is to say, we grouped students who agreed with $0 \%-$ $20 \%, 21 \%-40 \%, 41 \%-60 \%, 61 \%-80 \%$, and $81 \%-100 \%$ of the materialistic items; (ii) for each group the average of agreement with the materialistic and scientific items was calculated; (iii) for each group the average of confidence with both the materialistic and scientific items was calculated. The results are presented in Table III. As can be seen from the Table, students who agreed with only $0 \%-20 \%$ of the materialistic items agreed with more than $90 \%$ of the scientific items, and vice versa, with those students who agreed with $80 \%-100 \%$ of the materialistic items agreeing with only $64 \%$ of the scientific items. This means that those who view sound as more of a process phenomenon attribute fewer materialistic properties to it, and vice versa. In addition, as can be seen from Table III, the majority of students view sound as both material as well as process, simultaneously. In fact, 315 students agreed with $41 \%-60 \%$ of the materialistic items while at the same time agreeing with $65 \%$, on average, of the scientific items.

To strengthen our results, we repeated the same process with the scientific items. We grouped the participants according to their agreement with the scientific items. The results of this analysis are presented in Table IV. As can

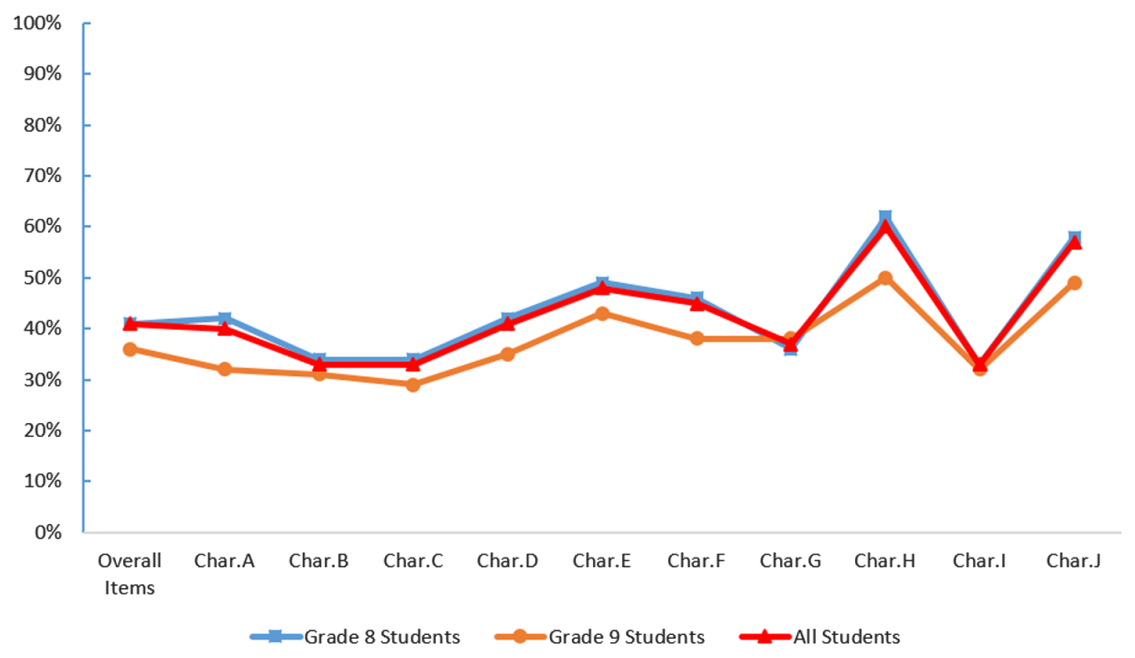

FIG. 1. Average percentage of correctness for each of the materialistic properties in the sound substance scheme, of all students and according to grade level (Char.A, Sound is invisible material; Char.B, Sound has a corpuscular nature; Char.C, Sound is pushable by objects; Char.D, Sound is pushable by medium; Char.E, Sound is frictional; Char.F, Sound is containable; Char.G, Sound is consumable; Char.H, Sound is gravity sensitive; Char.I, Hearing is influenced by the sound particle's size or number; Char.J, Sound is able to pass in a vacuum) 
TABLE III. Distribution of the participants with varied scores in items about materialistic properties. Note that " $M$ items" represent items regarding the materialistic property of sound; "S items" represent items regarding the process property of sound.

\begin{tabular}{|c|c|c|c|c|c|c|c|}
\hline $\begin{array}{l}\text { Agreement of } M \\
\text { items }(\%)\end{array}$ & $N$ & $\begin{array}{c}\text { Mean of } M \text { items } \\
\text { (Agreement) }\end{array}$ & $\begin{array}{c}\text { Confidence of } M \\
\text { items }\end{array}$ & $\begin{array}{c}\text { Correct-ness of } M \\
\text { items }\end{array}$ & $\begin{array}{c}\text { Mean of } S \\
\text { items }\end{array}$ & $\begin{array}{c}\text { Confidence of } S \\
\text { items }\end{array}$ & $\begin{array}{c}\text { Correct-ness } \\
\text { of all }\end{array}$ \\
\hline $0-20$ & 104 & $0.08(0.08)$ & $3.11(1.15)$ & $0.92(0.08)$ & $0.92(0.10)$ & $3.09(1.15)$ & $0.92(0.08)$ \\
\hline $21-40$ & 241 & $0.34(0.05)$ & $3.29(.77)$ & $0.66(0.05)$ & $0.71(0.13)$ & $3.21(0.78)$ & $0.68(0.06)$ \\
\hline $41-60$ & 315 & $0.50(0.06)$ & $3.29(.77)$ & $0.50(0.06)$ & $0.65(0.14)$ & $3.23(0.76)$ & $0.55(0.06)$ \\
\hline $61-80$ & 56 & $0.68(0.05)$ & $3.43(.94)$ & $0.32(0.05)$ & $0.64(0.20)$ & $3.36(0.94)$ & $0.42(0.07)$ \\
\hline $81-100$ & 16 & $0.87(0.06)$ & $3.16(1.52)$ & $0.13(0.06)$ & $0.64(0.38)$ & $3.10(1.49)$ & $0.30(0.14)$ \\
\hline
\end{tabular}

TABLE IV. Distribution of the participant with varied scores in items about scientific properties. Note that $M$ items represent items regarding the materialistic property of sound; $S$ items represent items regarding the process property of sound.

\begin{tabular}{|c|c|c|c|c|c|c|c|}
\hline $\begin{array}{l}\text { Agreement of } S \\
\text { items }(\%)\end{array}$ & $N$ & $\begin{array}{l}\text { Mean of } S \\
\text { items }\end{array}$ & $\begin{array}{c}\text { Confidence of } S \\
\text { items }\end{array}$ & $\begin{array}{l}\text { Mean of } M \text { items } \\
\quad \text { (Agreement) }\end{array}$ & $\begin{array}{c}\text { Correct-ness of } M \\
\text { items }\end{array}$ & $\begin{array}{l}\text { Confidence of } M \\
\text { items }\end{array}$ & $\begin{array}{c}\text { Correct-ness } \\
\text { of all }\end{array}$ \\
\hline $0-20$ & 9 & $0.14(0.09)$ & $2.08(0.93)$ & $0.73(0.23)$ & $0.27(0.23)$ & $2.15(1.02)$ & $0.23(0.18)$ \\
\hline $21-40$ & 14 & $0.36(0.04)$ & $3.13(0.67)$ & $0.56(0.11)$ & $0.44(0.11)$ & $3.21(0.67)$ & $0.42(0.08)$ \\
\hline $41-60$ & 241 & $0.55(0.06)$ & $3.06(0.76)$ & $0.47(0.11)$ & $0.53(0.11)$ & $3.14(0.78)$ & $0.54(0.08)$ \\
\hline $61-80$ & 245 & $0.72(0.05)$ & $3.28(0.82)$ & $0.42(0.12)$ & $0.58(0.12)$ & $3.35(0.81)$ & $0.62(0.09)$ \\
\hline $81-100$ & 223 & $0.91(0.06)$ & $3.34(0.97)$ & $0.30(0.24)$ & $0.70(0.24)$ & $3.38(0.98)$ & $0.77(0.17)$ \\
\hline
\end{tabular}

be seen from the Table, again, those students who agreed with only $0 \%-20 \%$ of the scientific items agreed with $73 \%$, on average, of the materialistic items, and vice versa, while those who agreed with $81 \%-100 \%$ of the scientific items agreed with only $30 \%$, on average, of the materialistic items. Again, as can be seen from the Table, many students viewed sound as both process as well as material.

\section{E. Grade differences}

As can be seen from Table V, the grade 8 students' scores were higher than those of the grade 9 students $(0.51$ vs $0.48)$. It is interesting to note that there were no significant differences between grade 8 and 9 students in the average level of agreement with the scientific items. The differences between the two grades are in their average level of agreement with the materialistic items (0.59 vs 0.64$)$. It is also interesting to note that the level of confidence of the grade 8 students, on average, with both the materialistic and the scientific items was higher than that of the grade 9 students.

\section{F. Gender differences}

As can be seen in Table VI, the girls scored significantly higher than the boys. The girls' mean score of agreement with the scientific items was higher than that of the males, although not significantly; however, the girls' mean score of agreement with the materialistic items was significantly lower $(t=-2.28, p<0.05)$. It is also interesting to note that the level of confidence of the boys for the materialistic items was higher $(t=2.06, p<0.05)$.

\section{DISCUSSION}

In light of the importance of the subject of sound for school students, and at the same time the lack of educational research concerning students' understanding of

TABLE V. Grade differences [Yr8 $N=614$ (83.88\%); Yr9 $N=118(16.12 \%)$ ].

\begin{tabular}{|c|c|c|c|c|c|c|c|}
\hline Issue & Grade level & Mean & $\mathrm{SD}$ & $t$ & $\begin{array}{c}\text { Mean of } \\
\text { Confidence }\end{array}$ & $\mathrm{SD}$ & $t$ \\
\hline \multirow[t]{2}{*}{ Total } & Yr8 & 0.51 & 0.11 & \multirow[t]{2}{*}{$2.38^{\mathrm{a}}$} & 3.32 & 0.81 & \multirow[t]{2}{*}{$4.81^{\mathrm{b}}$} \\
\hline & Yr9 & 0.48 & 0.12 & & 2.91 & 1.05 & \\
\hline \multirow[t]{2}{*}{ Process properties } & Yr8 & 0.70 & 0.16 & \multirow[t]{2}{*}{-0.95} & 3.27 & 0.81 & \multirow[t]{2}{*}{$3.75^{\mathrm{b}}$} \\
\hline & Yr9 & 0.72 & 0.22 & & 2.89 & 1.05 & \\
\hline \multirow{2}{*}{$\begin{array}{l}\text { Materialistic properties } \\
\text { (mean of agreement } \\
\text { with materialistic items) }\end{array}$} & Yr8 & 0.59 & 0.17 & \multirow[t]{2}{*}{$2.17^{\mathrm{a}}$} & 3.34 & 0.81 & \multirow[t]{2}{*}{$4.13^{\mathrm{t}}$} \\
\hline & Yr9 & 0.64 & 0.24 & & 2.91 & 1.06 & \\
\hline
\end{tabular}


TABLE VI. Gender differences [Male $N=364(49.73 \%)$; Female $N=368(50.27 \%)$ ].

\begin{tabular}{|c|c|c|c|c|c|c|c|}
\hline Issue & Gender & Mean & SD & $t$ & Mean of confidence & SD & $t$ \\
\hline \multirow[t]{2}{*}{ Total } & Male & 0.49 & 0.11 & $-3.59^{\mathrm{b}}$ & 3.31 & 0.92 & 1.90 \\
\hline & Female & 0.52 & 0.10 & & 3.19 & 0.80 & \\
\hline \multirow[t]{2}{*}{ Process properties } & Male & 0.69 & 0.18 & -1.84 & 3.26 & 0.91 & 1.53 \\
\hline & Female & 0.72 & 0.16 & & 3.16 & 0.82 & \\
\hline \multirow{2}{*}{$\begin{array}{l}\text { Materialistic properties } \\
\text { (mean of agreement } \\
\text { with materialistic items) }\end{array}$} & Male & 0.61 & 0.20 & $-2.28^{\mathrm{a}}$ & 3.34 & 0.93 & $2.06^{\mathrm{a}}$ \\
\hline & Female & 0.58 & 0.17 & & 3.20 & 0.81 & \\
\hline
\end{tabular}

sound, and especially quantitative studies, the present study aimed at examining Taiwanese middle school students' materialistic views of sound. For this purpose, the SCII was used. The KR-20 of the entire instrument (0.75) and its subcategories (materialistic items, 0.88; scientific items, 0.73 ) provide further supports for the reliability of the SCII. In addition, as was mentioned in the methodological section, the SCII, which is a student-centered diagnostic tool, enables the students to add their own explanations to the phenomena they were presented with. However, only some students suggested answers other than what they were provided with in the statements. Most of these answers were just another wording or clarification of the answers which already appeared in the SCII. Although beyond the scope of the present research, this provides further support for Eshach's [4] argument that scientific and materialistic views are probably the most significant views middle school students hold regarding sound.

The results of this study agree with other research showing that the subject of sound poses a great challenge for students. In spite of the fact that 8 th grade students in Taiwan learn the subject in depth, the students, in general, got relatively low scores (only 50\% of the answers, on average, were correct). They agreed, on average, with $59 \%$ of the materialistic statements. They were also confident in their answers. Furthermore, the students associated sound with most of the materialistic properties described in the sound substance scheme. It seems that as Reiner et al. [9] suggested, students might have a coherent knowledge concerning substance, which they use when confronted with new phenomena. In addition, it was found that in parallel with the materialistic view of sound, students hold a scientific view as well. This is clear evidence that although students learn about waves, they still have in mind a materialistic view of sound which probably serves as a barrier to gaining a good understanding of the subject.

An in-depth analysis was conducted in order to examine whether those who attributed sound to more materialistic items also attributed it to fewer scientific items. To this end, we divided the research population into five groups according to the level of their agreement with materialistic properties (agreement with the following percentage of materialistic items: $0 \%-20 \%, 21 \%-40 \%, 41 \%-60 \%$,
$61 \%-80 \%, 81 \%-100 \%$ ), and calculated their level of agreement with the scientific items. The results of this analysis yielded that the higher the percentage of materialistic items, the lower the percentage of agreement with the process (scientific) items, and vice versa. A similar finding was also made when we divided the research population into five groups according to the level of their agreement with the process properties, i.e., the scientific items, and then calculated the level of percentage of agreement with the materialistic properties. It seems that although most of the students hold both materialistic and process (scientific) views of sound, still, the stronger the materialistic view, the weaker the process view, and vice versa.

This result may be explained by Vosniadou and Brewer's [25] framework theory. Framework theories are skeletal structures that ground people's deepest ontological commitments and form the means by which people understand the world. It should be noted that the term "theory" is different from what one may have in mind when he or she thinks of the term "scientific theory." The use of the term theory highlights the fact that each framework theory represents a relatively coherent body of knowledge characterized by a distinct ontology and causality. This coherent body of knowledge, the framework theory, can give rise to students' prediction and explanation. According to the framework theory, by the time they start primary school, children have developed naïve physics framework theories that provide intuitive explanations of everyday phenomena. These early conceptual structures are very different from the scientific concepts to which children are exposed through instruction. Thus students' initial conceptual structures need to be changed in the process of knowledge acquisition-new concepts, new ontological categories, new representations, and new explanations. To acquire new knowledge students not only need to enrich their existing conceptual structures, they also need to radically reorganize what they already know. Many misconceptions are synthetic models that reveal students' attempts to assimilate the new information to their existing knowledge base. We argue that the materialistic view of sound may be considered as a kind of a framework theory; one may call it the material framework theory. This means that before learning formally about sound the students had already 
constructed for themselves a coherent naïve physics body of knowledge regarding sound phenomena that can be characterized by a distinct materialistic ontology described by what we call the material framework theory. Students try to explain different phenomena in light of this materialistic framework. In grade 8, Taiwanese students start to learn about the concept of sound in more depth. The new information students are exposed to in school conflicts with the materialistic-based conception of sound that the students have developed as a result of their day-to-day experiences before the formal instruction. According to the framework theory, the process of bridging the gap between the new and existing information results in a synthetic model that consists of elements of both the old and the new information. This may explain why students, even after extensive learning of the subject, possess both materialistic as well as process views of sound simultaneously. Indeed, as the framework theory suggests, the conceptual change process is a slow and gradual process of knowledge revision and not a sudden change from one coherent theory (the before learning existing materialistic-based body knowledge structure) to another (the scientific body knowledge). It is interesting to note in this regard that after the formal learning in grade 8 , there is a regression to the materialistic view, with the grade 9 students' percentage of agreement with the materialistic items significantly higher than that of the 8th graders.

One suggestion for teaching the concept of sound is to acknowledge the fact that students' materialistic view of sound is a rigorous one and to take it into account in the teaching process, both in class and in textbooks. Indeed, since long ago, it is known that the form in which something is presented in the textbook can influence students' learning in unexpected way. Recent experimental evidence is even related to sound phenomena [26]. Thus, the teachers as well as textbooks should challenge materialistic views by some conceptual-change learning activities or conceptual questions. Teachers should clearly discuss with their students the materialistic view of sound and guide their students to understand the problems or inconsistencies with it. This agrees with Clement's suggestion [27] that naive materialistic conceptions might provide a good starting point for instruction, especially in the case of sound, which, after all, is a materialistic-related phenomenon. Indeed, "to simply start presenting basic physics concepts through nonmaterialistic representation ...might strip the students of all of the tools and experience patterns they have constructed to make sense of things" (Ref. [9], p. 29). One way to address this suggestion is to discuss questions such as in the SCII. Teachers should also discuss explicitly the idea that some of the materialistic concepts may stem from the everyday language. Vibrations, waves, or oscillations, and matter are all related. For instance, the term waves is perceived by many as something "real" which goes up and down, like the water in the sea. Thus, understanding that the term "waves" is different from what we usually have in mind while using it, and understanding what is indeed waving might help students to gain a better understanding of the concept of sound. Another option is to use historical materialistic explanations of sound phenomena and discuss them in class (for examples of such cases see Ref. [5]).

In addition, the regression to more materialistic thinking of grade 9 students, who do not study sound, suggests that to overcome the materialistic thinking barrier in a meaningful way students need to revisit their scientific view of sound while learning relevant concepts. We know that due to time limits and the need to cover other topics, this might be impossible. However, creative ways of doing so might be found. For instance, while the students learn about other subjects, such as, say, light, the teacher can ask them to compare light and sound.

Our findings that the girls scored higher than the boys is surprising in light of previous research showing that boys' test scores in physics tend to be higher than those of girls [28]. Such a gap can be explained by the male students' materialistic view regarding sound concepts. The apparent materialistic concepts of male students, together with the expectation of better performance in science learning from their teachers or themselves, may reinforce their corresponding confidence. It should be noted that the questions in the SCII are quantitative and check the respondents' true understanding rather than just requiring the manipulation of some formulas. Zohar and Sela [28] argued that methods which foster students' understanding while decreasing competitiveness in physics classes might contribute to girls' participation and performance in advanced physics classes. By contrast, the gender difference of sound concepts revealed in this study reflects the necessity to provide male students with more opportunities to especially challenge their existing misconceptions from the materialistic perspective.

The rich literature regarding students' scientific misconceptions shows that many science concepts are extremely hard and thus lead to students' difficulties in learning with deep understanding. This also contributes to students' stable and robust misconceptions that are resistant to instruction [29]. The present study clearly shows that sound is such a scientific concept. The results also show that students view sound as belonging to both material and process categories simultaneously. This agrees with Vosniadou and Brewer's [25] framework theory, which implies that in the slow and gradual process of conceptual change, one may simultaneously hold two different theories or parts of theories. Furthermore, the present study found that in this process a regression to the old category may occur. Teachers should be aware of the influence of the materialistic view of sound on students' conceptual change process and take it into account in their teaching. 


\section{ACKNOWLEDGMENT}

This study was supported by Ministry of Science and Technology, Taiwan (Grant No. MOST 103-2511-S-011003-MY3).

[1] D. Layton, Science for the People: The Origins of the School Science Curriculum in England (George Allen \& Unwin Ltd., London, 1973).

[2] I. Caleon and R. Subramaniam, Development and application of a three-tier diagnostic test to assess secondary students' understanding of waves, Int. J. Sci. Educ. 32, 939 (2010).

[3] Z. Hrepic, D. A. Zollman, and N. S. Rebello, Identifying students' mental models of sound propagation: The role of conceptual blending in understanding conceptual change, Phys. Rev. ST Phys. Educ. Res. 6, 020114 (2010).

[4] H. Eshach, Development of a student-centered instrument to assess middle school students' conceptual understanding of sound, Phys. Rev. ST Phys. Educ. Res. 10, 010102 (2014).

[5] H. Eshach and J. Schwartz, Sound Stuff? Naïve materialism in middle school students' conceptions of sound, Int. J. Sci. Educ. 28, 733 (2006).

[6] OECD, PISA 2012 results: What Students Know and Can Do-Student Performance in Mathematics, Reading and Science (Volume I, Revised edition, February 2014) (PISA, OECD Publishing, Paris, 2014).

[7] S. Provasnik, D. Kastberg, D. Ferraro, N. Lemanski, S. Roey, and F. Jenkins, Highlights from TIMSS 2011: Mathematics and Science Achievement of U.S. Fourthand Eighth-Grade Students in an International Context (NCES 2013-009) (National Center for Education Statistics, Institute of Education Sciences, U.S. Department of Education, Washington, DC, 2012).

[8] R. Stavy, V. Goel, H. Critchley, and R. Dolan, Intuitive interference in quantitative reasoning, Brain Res. 10731074, 383 (2006).

[9] M. Reiner, J. D. Slotta, M. T. H. Chi, and L. B. Resnick, Naïve physics reasoning: A commitment to substancebased conceptions, Cognit. Instr. 18, 1 (2000).

[10] E. Boyes and M. Stanisstreet, Development of pupils' ideas about seeing and hearing - the path of light and sound, Res. Sci. Technol. Educ. 9, 223 (1991).

[11] H. M. Asoko, J. Leach, and P. H. Scott, A study of students' understanding of sound 5-16 as an example of action research, Proceedings of the Annual Conference of the British Educational Research Association (Roehampton Institute, London, 1990).

[12] M. T. H. Chi, Cognitive Models of Science: Minnesota Studies in the Philosophy of Science, edited by R. Giere (University of Minnesota Press, Minneapolis, MN, 1992), pp. 129-160.

[13] M. T. H. Chi and J. D. Slotta, The ontological coherence of intuitive physics, Cognit. Instr. 10, 249 (1993).
[14] M. T. H. Chi, J. D. Slotta, and N. A. de Leeuw, From things to processes: A theory of conceptual change for learning science concepts, Learn. Instr. 4, 27 (1994).

[15] J. Lautrey and L. Mazens, Is children's naive knowledge consistent? A comparison of the concepts of sound and heat, Learn. Instr. 14, 399 (2004).

[16] R. Driver, A. Squires, P. Rushworth, and V. WoodRobinson, Making Sense of Secondary Science (Routledge, London, UK, 1994).

[17] D. Watt and T. Russel, Sound, Primary SPACE Project Research Report (Liverpool University Press, Liverpool, UK, 1990).

[18] E. West and A. Wallin, Students' learning of a generalized theory of sound transmission from a teaching-learning sequence about sound, hearing and health, Int. J. Sci. Educ. 35, 980 (2013).

[19] A. G. Ryan and G. S. Aikenhead, Students' preconceptions about the epistemology of science, Sci. Educ. 76, 559(1992).

[20] R. J. Beichner, Testing student interpretation of kinematics graphs, Am. J. Phys. 62, 750 (1994).

[21] S. Hasan, D. Bagayoko, and E. L. Kelley, Misconceptions and the certainty of response index (CRI), Phys. Educ. 34, 294 (1999).

[22] C. H. Renner and M. J. Renner, But I thought I knew that: Using confidence estimation as a debiasing technique to improve classroom performance, Appl. Cogn. Psychol. 15, 23 (2001).

[23] L. Ding and R. Beichner, Approaches to data analysis of multiple choice questions, Phys. Rev. ST Phys. Educ. Res. 5, 020103 (2009).

[24] J. F. Hair, W. C. Black, B. J. Babin, and R. E. Anderson, Multivariate Data Analysis, 7th ed. (Prentice Hall, Upper Saddle River, NJ, 2010).

[25] S. Vosniadou and W. F. Brewer, Mental models of the day/ night cycle, Cogn. Sci. 18, 123 (1994).

[26] L. Zeng, C. Smith, G. H. Poelzer, J. Rodriguez, E. Corpuz, and G. Yanev, Illustrations and supporting texts for sound standing waves of air columns in pipes in introductory physics textbooks, Phys. Rev. ST Phys. Educ. Res. 10, 020110 (2014).

[27] J. Clement, in Proceeding of the Second International Seminar Misconceptions and Education Strategies in Science and Mathematics, edited by J. D. Novak (Cornell University, Ithaca, NY, 1987), pp. 84-96.

[28] A. Zohar and D. Sela, Her physics, his physics: Gender issues in Israeli advanced placement physics classes, Int. J. Sci. Educ. 25, 245 (2003).

[29] C. W. Anderson and E. Smith, in The Educator's Handbook: A Research Perspective, edited by V. RichardsonKoehler, (Longman, New York, 1987), pp. 84-111. 